\title{
Ultrasound Evaluation of Patients with Moderate and Severe Carpal Tunnel Syndrome
}

\author{
Moghtaderi A. ${ }^{1}$, Sanei-Sistani S. ${ }^{2}$, Sadoughi N. ${ }^{2}$, Hamed-Azimi H. ${ }^{3}$ \\ ${ }^{1}$ Department of Neurology, Zahedan University of Medical Sciences, Zahedan, Iran; \\ ${ }^{2}$ Department of Radiology, Zahedan University of Medical Sciences, Zahedan, Iran; \\ ${ }^{3}$ Department of Operative Orthopedics, Zahedan University of Medical Sciences, \\ Zahedan, Iran
}

Received April 29, 2011; Accepted January 16, 2012.

Key words: Ultrasound - Carpal tunnel syndrome - Median neuropathy Case-control study

\begin{abstract}
The objective of this study is to determine cut-off points for the crosssectional areas of the median nerve proximal and distal to carpal tunnel in moderate and severe Carpal Tunnel Syndrome (CTS) and compare the results of our study with those available in the literature. Forty-three patients with upper limb pain other than CTS and 36 patients with idiopathic CTS enrolled into the study. The diagnosis and categorization of CTS were based on electrophysiologic criteria of the American Academy of Neurology. Median nerve cross-sectional areas were measured. Arithmetic mean values and standard deviation of each variable were measured. Student $t$-test and chi-squared test were applied to compare continuous and dichotomous variables between CTS and non-CTS control groups. Ultimately the diagnostic performances of the test characteristics including sensitivity, specificity, positive and negative predictive values were measured. Mean cross-sectional area of the nerve is higher in moderate than severe CTS proximal and distal to carpal tunnel. We accepted cut-off points of $11.5 \mathrm{~mm}^{2}$ and $13.5 \mathrm{~mm}^{2}$ for cross-sectional areas of the proximal and distal portions of carpal canal respectively. The sensitivity, specificity, positive and negative predictive values for the proximal inlet are $83 \%$, 90.7\%, 65.5\% and 55.7\%; and for the distal outlet are 36.1\%, 93\%, 81.2\% and $63.4 \%$ respectively. We suggest that ultrasound is a good diagnostic modality for patients referred to tertiary care centers which categorized as moderate CTS.
\end{abstract}

Mailing Address: Assoc. Prof. Ali Moghtaderi, MD., Department of Neurology, Zahedan University of Medical Sciences and Imam-Ali Teaching Hospital, 9815733169 Zahedan, Iran; Phone: +98 541323 4551; Fax: +98 541321 8848; e-mails: moghtaderi@zaums.ac.ir, amoghtaderi@gmail.com 


\section{Introduction}

Carpal tunnel syndrome (CTS) is the most frequent entrapment neuropathy of the human beings encountered in general population (Dawson, 1993). Entrapment of the median nerve in carpal tunnel is the main pathophysiological factor resulting in the ischemia, edema, demyelination and ectopic impulse generation of the neural trunk (Werner and Andary, 2002). Diagnosis is based on symptoms such as pain, numbness and/or burning sensation distributed in the territory of the nerve and confirmed by electrophysiological study of the median nerve and innervated muscles (Nora et al., 2004). Until recently ultrasound (US) study of the nerve does not have practical value for the diagnosis of CTS. Several studies have demonstrated that US could be used to increase the sensitivity and specificity of diagnosis in combination with clinical and electrophysiological findings (Sernik et al., 2008). It is also useful to depict the anatomical variation of the nerve, different etiologies of the CTS such as synovitis, nodular deposits and to determine the best type of surgical procedure needed for the patients (Sarria et al., 2000). The main consensus in medical literature is finding a sonographic cut-off point for the diagnosis of carpal tunnel syndrome. The objective of this study is to determine a cut-off point for the cross-sectional areas of the median nerve proximal to inlet and distal to outlet of carpal tunnel in moderate and severe CTS in a local Iranian population and also to compare the results of our study with those available in the literature.

\section{Material and Methods}

Patient selection

After getting the university ethics committee approval, we conducted a casecontrol study in our out-patient clinic. From November 2007 to September 2008, 43 patients with upper limb pain other than CTS and 36 patients with idiopathic moderate and severe CTS with clinical and electrophysiological confirmation entered into the study consecutively. All participants were residents of one urban area. Non-CTS control group had different types of musculoskeletal, articular and/or soft tissue pain which ultimately had been confirmed by different diagnostic procedures. Electrophysiological study in this group was normal. After explaining the nature of the work and obtaining informed consent for the study, the examiner filled out a questionnaire about participants' age, gender, occupation, any associated disorder, pregnancy, diabetes, trauma and fracture in the upper limbs. The patients had no history or clinical signs suggesting systemic disease, and no clinical or electrophysiological signs suggesting pathological conditions such as polyneuropathy, radiculopathy, weakness and atrophy in muscles innervated by other nerves and previous surgery on median nerve or upper limb.

\section{Electrophysiological study}

The diagnosis of CTS was based on history, clinical findings (paresthesia, pain, clumsiness and nocturnal symptoms) and electrodiagnostic criteria according to the 
American Academy of Neurology (AAN) (2002) consisting of neurographic evidence of slowing of distal median nerve conduction. All electrodiagnostic studies with a Medelec Oxford-Synergy apparatus (Oxford, UK) were done by a single person (AM, a member of the authors' team). All studies were done on subjects lying on a bed in the same quiet warm room and in similar temperature. All nerve stimulations were delivered with a constant current standard bipolar surface stimulator (cathode distal). The sweep speed was set at $2 \mathrm{~ms} /$ division and the recording of the median nerve compound muscle action potential (CMAP) was performed using two silver surface disks $(\mathrm{Ag} / \mathrm{AgCl})$ with a standard size of $4 \times 7 \mathrm{~mm}$, which were placed on the thenar muscle at a distance of $8 \mathrm{~cm}$ from the stimulator. CMAP for median nerve was calculated from the baseline to the negative peak. Interelectrode distance (between active and reference electrodes) was $4 \mathrm{~cm}$. Sensory nerve action potentials (SNAPs) were obtained antidromically, using ring electrode after stimulation at the wrist and registered at second digit for the median nerve and at fifth digit in the same way for ulnar nerve. Active and reference electrodes were placed on proximal and distal interphalangeal joints respectively with interelectrode distance of $2 \mathrm{~cm}$. Sometimes it needed measuring SNAP at the first or third digits using corresponding standards. Supramaximal stimulation was used for motor conduction studies, while up to $50 \mathrm{~mA}$ stimulation intensity was delivered for sensory nerves. Sensory responses obtained were averaged. Maximum antidromic sensory conduction velocity (SCV) and maximum sensory action potential amplitude (SAP) were determined. The mean values of distal latencies, conduction velocities and amplitudes were calculated for motor and sensory branches of median nerve. Normal reference values for age and sex were based on a previous local population study of healthy subjects in this region. After an evaluation of the assumption of normal distribution, abnormal values were defined as more than two standard deviations (SD) of normal mean values. Distal and peak latencies for sensory branches of median nerve in CTS and non-CTS patients were measured. Electromyographic study was carried out in all individuals. Electrophysiological diagnostic criteria of CTS should include at least two of the following: (Stevens, 1997) (i) prolonged distal latency of motor fibers of median nerve $\geq 4 \mathrm{~ms}$; (ii) prolonged median nerve digit 2 sensory onset latency $\geq 2.5 \mathrm{~ms}$; (iii) prolongation of onset latency of the median SNAP of digit two relative to the ulnar SNAP of digit five $\geq 0.5 \mathrm{~ms}$. Normal median conduction velocity along the forearm was mandatory (\#50 m/s). Those parameters are used as the reference values for the diagnosis of CTS in our electromyography laboratory. Our patients were divided into three groups on the basis of electrophysiological severity: (Stevens, 1997) (i) Mild: prolonged sensory distal latency \pm SNAP amplitude reduction;

(ii) Moderate: prolongation of both median motor and sensory distal latencies;

(iii) Severe: electrodiagnostic criteria of moderate type of CTS, with either an absence of SNAP, or low amplitude or absent thenar CMAP, or findings compatible with axonal injury in electromyography. Patients with moderate and severe CTS were entered into the study. 


\section{Ultrasound imaging}

All patients underwent high resolution real-time sonography of the carpal tunnel using a GE Voluson-370 ultrasound system (GE Medical Systems, USA) with 10-13 $\mathrm{MHz}$ linear array transducer. A board certified radiologist with practical experience (SSS) who was blinded to clinical and electrophysiologic findings performed all examinations. All patients were seated in a comfortable position, the supinated forearm lying on a table; wrist and fingers were extended respectively. The palm was facing up in the neutral position and the volar wrist crease used as the initial surface marker. For subsequent modification during US scanning, carpal bony landmarks were used as the internal reference points. US examination was done in the same day or within two days after the electrophysiological study. Axial images of the nerve in two anatomical levels, proximal to inlet (proximal edge of flexor retinaculum) and distal to outlet of carpal tunnel were obtained and reproduced until the best images were provided. The qualitative evaluation of the nerve echogenicity and the quantitative evaluation of the median nerve cross-sectional areas at the carpal tunnel inlet proximally and outlet distally were done throughout each examination. Distal edge of flexor retinaculum and wrist crease were anatomical markers for the distal and proximal carpal tunnel respectively. Using the machine's software, the radiologist calculated median nerve cross-sectional hypoechoic area directly (tracing method) by marking and outlining the nerve contour (Buchberger et al., 1991; Colak et al., 2007; Sernik et al., 2008). All measurements were finally rounded to the nearest $0.01 \mathrm{~cm}^{2}$.

\section{Statistical analysis}

After an evaluation of the assumption of normal distribution by using SPSS software for Windows, version 11 (SPSS Inc., Chicago, IL, USA), arithmetic mean values and standard deviations (SD) of the data were calculated. Then we carried out an unpaired two sample $t$-test and chi-squared test comparing age and sex between CTS and non-CTS groups. A repeated measure of analysis of variance (ANOVA) was applied to compare dichotomous and continuous variables between non-CTS group and two CTS subgroups. Ultimately performance characteristics of the test including sensitivity, specificity, positive and negative predictive values were measured. Various cut-off values were calculated to determine the best median nerve cross-sectional area. A two-sided significance level of 0.05 was used.

\section{Results}

We studied a total of 94 patients in our outpatient clinic. Seventy-nine hands of 79 patients met the criteria to enter the study. Fifteen hands were excluded because of nerve bifurcation, anomalies or difficulties with assessing the nerve contour in the palm region. They aged between 20 and 58 years and 66 cases were females. According to the above criteria 24 patients had moderate and 12 cases had severe CTS. Comparing two groups based on age and sex, there was not any statistical differences between them. Age range for the non-CTS group was between 20 and 


\section{Table 1 - Mean cross-sectional areas of median nerve in CTS patients and control group according to the anatomical location}

\begin{tabular}{lccc}
\hline Location & $\begin{array}{c}\text { Number } \\
\text { of cases }\end{array}$ & $\begin{array}{c}\text { Proximal to canal } \\
\text { mean }\left(\mathrm{mm}^{2}\right) \pm \mathrm{SD} \\
(95 \% \mathrm{Cl})\end{array}$ & $\begin{array}{c}\text { Distal to canal } \\
\text { mean }\left(\mathrm{mm}^{2}\right) \pm \mathrm{SD} \\
(95 \% \mathrm{Cl})\end{array}$ \\
Groups & 43 & $6.55 \pm 2.40(5.81-7.29)$ & $9.27 \pm 3.69(8.14-10.41)$ \\
Control group & 24 & $8.87 \pm 2.60(7.78-9.96)$ & $12.62 \pm 4.10(10.88-14.36)$ \\
CTS patients (moderate) & 12 & $6.75 \pm 1.65(5.69-7.80)$ & $11.75 \pm 3.36(9.61-13.88)$ \\
CTS patients (severe) & 12 & $<0.001$ & $<0.002$ \\
\hline p-value between 3 groups & - & &
\end{tabular}

55 with a mean of $39.7 \pm 6.9$ years and age range for the CTS group was between 22 and 58 with a mean of $45.0 \pm 6.1$ years. Student $t$-test for comparing mean of age values in two groups did not reveal any significant statistical difference $(p=0.338)$ among two groups. Thirty-two females were in the CTS group and 34 females in the non-CTS group. The remainders were male. Fisher exact test did not reveal statistical significant difference between two groups $(p=0.362)$. A repeated measure of analysis of variance (ANOVA) comparing the mean sonographic values of control group and two subgroups of CTS patients showed significant differences for direct measurement of cross sectional areas proximal and distal to carpal tunnel (F-ratio $=7.754, p=0.001 ;$ F-ratio $=6.595, p=0.002$ ) respectively $($ Table 1$)$. According to the assumption that our data has been normally distributed and by using a receiver operating characteristic curve, we accepted cut-off points of $11.5 \mathrm{~mm}^{2}$ and $13.5 \mathrm{~mm}^{2}$ for cross-sectional areas of the proximal and distal portions of carpal canal respectively. The test performance characteristics including sensitivity, specificity, positive predictive value, negative predictive value and likelihood ratio for a positive result (positive LR) for the proximal inlet (proximal edge of flexor retinaculum) of the carpal canal were $83 \%, 90.7 \%, 65.5 \%, 55.7 \%, 8.90$ and for the distal outlet were $36.1 \%, 93 \%, 81.2 \%, 63.4 \%$ and 5.16 respectively. The areas under the ROC curve were 0.801 for proximal inlet and 0.659 for distal outlet.

\section{Discussion}

Previous studies showed that US is a feasible and reliable diagnostic procedure. Buchberger et al. $(1991,1992)$ were the first researchers who assessed the crosssectional area of the median nerve using a high resolution US machine with a $7 \mathrm{MHz}$ transducer to confirm the previously reported MR imaging of the carpal tunnel. Compression of the median nerve in the canal may increase diagnostic yield of the ultrasound. US is cheaper and faster than MRI, therefore it may increase the importance of this diagnostic modality in comparison to MRI (Beekman and Visser, 2003; Wong et al., 2004). The main consensus of the other studies was to specify quantitative reliable cut-off values and other qualitative US criteria for the diagnosis of CTS (Nakamichi and Tachibana, 2002; El Miedany et al., 2004; Keles et al., 2005). 
Table 2 - Ultrasound cut-off points for diagnosis of CTS using cross-sectional areas of the median nerve

\begin{tabular}{|c|c|c|c|c|c|}
\hline Study & $\begin{array}{c}\text { Cut-off point } \\
\left(\mathrm{mm}^{2}\right) / \text { location* }^{*}\end{array}$ & Sensitivity & Specificity & PPV & NPV \\
\hline Abicalaf et al. (2007) & $\geq 10 / P$ & NA & NA & NA & NA \\
\hline Colak et al. (2007) & $\begin{array}{c}\geq 7 / \mathrm{NA} \\
\text { (severe CTS) }\end{array}$ & $89.0 \%$ & $83.0 \%$ & NA & NA \\
\hline Duncan et al. (1999) & $\geq 9 / M$ & $82.4 \%$ & $97.1 \%$ & $97.7 \%$ & $78.6 \%$ \\
\hline Kele et al. (2003) & $\geq 11 / P$ & $73.6 \%$ & $98.0 \%$ & $98.8 \%$ & $63.8 \%$ \\
\hline Keles et al. (2005) & $\begin{array}{l}\geq 9.3 / P \\
\geq 8.5 / M \\
\geq 9.5 / D\end{array}$ & $\begin{array}{l}80.0 \% \\
80.0 \% \\
82.9 \%\end{array}$ & $\begin{array}{l}77.5 \% \\
72.5 \% \\
70.0 \%\end{array}$ & $\begin{array}{l}\text { NA } \\
\text { NA } \\
\text { NA }\end{array}$ & $\begin{array}{l}\text { NA } \\
\text { NA } \\
\text { NA }\end{array}$ \\
\hline $\begin{array}{l}\text { Kotevoglu and } \\
\text { Gulbahce-Saglam (2005) }\end{array}$ & NA & $89.0 \%$ & $100 \%$ & $100 \%$ & $84.0 \%$ \\
\hline Kwon et al. (2008) & $\geq 10.7 / P$ & $66.0 \%$ & $63.0 \%$ & NA & NA \\
\hline Leonard et al. (2003) & $\geq 11.6 / P$ & $72.0 \%$ & $90.0 \%$ & NA & NA \\
\hline \multirow[t]{2}{*}{ El Meidany et al. (2004) } & $\begin{array}{c}\geq 13.02 / M \\
\text { (moderate CTS) }\end{array}$ & $98.4 \%$ & $96.8 \%$ & NA & NA \\
\hline & $\begin{array}{c}\geq 15.02 / M \\
\text { (severe CTS) }\end{array}$ & $96.6 \%$ & $99.0 \%$ & NA & NA \\
\hline Nakamachi and & $\geq 13 / P$ & $57.0 \%$ & $97.0 \%$ & $94.0 \%$ & $69.0 \%$ \\
\hline Tachibana (2002) & $\begin{array}{l}\geq 11 / M \\
\geq 14 / D\end{array}$ & $\begin{array}{l}44.0 \% \\
43.0 \% \\
\end{array}$ & $\begin{array}{l}97.0 \% \\
96.0 \% \\
\end{array}$ & $\begin{array}{l}93.0 \% \\
91.0 \% \\
\end{array}$ & $\begin{array}{l}60.0 \% \\
62.0 \% \\
\end{array}$ \\
\hline Naranjo et al. (2007) & $\begin{array}{l}\geq 11 / P \\
\geq 13 / D\end{array}$ & $\begin{array}{l}63.7 \% \\
41.0 \% \\
\end{array}$ & $\begin{array}{l}72.0 \% \\
100 \% \\
\end{array}$ & $\begin{array}{l}\text { NA } \\
\text { NA }\end{array}$ & $\begin{array}{l}\text { NA } \\
\text { NA }\end{array}$ \\
\hline Sarria et al. (2000) & $\begin{array}{l}\geq 11 / P \\
\geq 11 / D\end{array}$ & $\begin{array}{l}35.0 \% \\
81.3 \% \\
\end{array}$ & $\begin{array}{l}57.1 \% \\
64.3 \% \\
\end{array}$ & $\begin{array}{l}72.7 \% \\
77.6 \% \\
\end{array}$ & $\begin{array}{l}60.0 \% \\
69.2 \% \\
\end{array}$ \\
\hline Sernik et al. (2008) & $\geq 10 / D$ & $85.0 \%$ & $92.1 \%$ & $87.2 \%$ & $90.6 \%$ \\
\hline Weisler et al. (2006) & $\geq 11 / P$ & $91.0 \%$ & $84.0 \%$ & $74.0 \%$ & $95.0 \%$ \\
\hline Wong et al. (2002) & $\begin{array}{l}\geq 8.8 / \mathrm{P} \\
\geq 8.5 / \mathrm{D} \\
\end{array}$ & $\begin{array}{l}74.0 \% \\
80.0 \% \\
\end{array}$ & $\begin{array}{l}63.0 \% \\
50.0 \% \\
\end{array}$ & $\begin{array}{l}67.0 \% \\
94.0 \% \\
\end{array}$ & $\begin{array}{l}71.0 \% \\
73.0 \% \\
\end{array}$ \\
\hline Wong et al. (2004) & $\begin{array}{l}9 / P ; \geq 12 / D \text { (right hand) } \\
\geq 10 / P ; D \text { (left hand) }\end{array}$ & $\begin{array}{l}94.0 \% \\
83.0 \%\end{array}$ & $\begin{array}{l}65.0 \% \\
73.0 \%\end{array}$ & $\begin{array}{l}\text { NA } \\
\text { NA }\end{array}$ & $\begin{array}{l}\text { NA } \\
\text { NA }\end{array}$ \\
\hline Yesildag et al. (2004) & $\geq 10.5 / P$ & $89.9 \%$ & $94.7 \%$ & $97.1 \%$ & $82.7 \%$ \\
\hline
\end{tabular}

*P for proximal to canal, $M$ for in the middle of canal, $D$ for distal to canal and NA for not accessible PPV - positive predictive value; NPV - negative predictive value

It should be reminded that standardization of the US techniques is a mandatory requirement before using this procedure as a routine diagnostic facility (Beekman and Visser, 2003).

In most studies median nerve dimensions were calculated in one anatomical location mostly in the proximal inlet of the carpal tunnel (Buchberger et al., 1991; Duncan et al., 1999; Kele et al., 2003; Leonard et al., 2003; El Miedany et al., 2004; Yesildag et al., 2004; Koyuncuoglu et al., 2005; Wiesler et al., 2006; Abicalaf et al., 
2007; Kwon et al., 2008; Sernik et al., 2008), but in some of them two anatomical levels were assessed (Wong et al., 2002, 2004; Keles et al., 2005; Colak et al., 2007; Naranjo et al., 2007) and in a few studies more than two levels of compression were assessed (Table 2) (Sarria et al., 2000; Nakamichi and Tachibana, 2002; Kotevoglu and Gulbahce-Saglam, 2005; Bayrak et al., 2007). Some of them were correlated to the US findings and electrophysiological grading (Nakamichi and Tachibana, 2002; El Miedany et al., 2004) and two studies are about accuracy of the US procedure (Wong et al., 2002; Ziswiler et al., 2005). Many of those studies have proposed the canal inlet as the best place to measure the nerve area. The reported critical crosssectional area of the median nerve varied between $9 \mathrm{~mm}^{2}$ and $11 \mathrm{~mm}^{2}$ (Beekman and Visser, 2003). Wong et al. (2004) proposed cut-off value for nerve swelling of $10 \mathrm{~mm}^{2}$ and $12 \mathrm{~mm}^{2}$ for the proximal inlet and distal outlet of the carpal tunnel respectively. The highest reported critical value is $15 \mathrm{~mm}^{2}$ for the proximal inlet of the canal (Beekman and Visser, 2003). The cut-off points shown in those studies were different according to the anatomical level of US images.

Concerning the above mentioned specificity and sensitivity the authors suggest cut-off points of $11.5 \mathrm{~mm}^{2}$ and $13.5 \mathrm{~mm}^{2}$ for the cross-sectional areas of the proximal and distal portions of the carpal canal respectively. Those cut-off values can discriminate a pathological mean cross-sectional area of the median nerve between cases versus the control group. On the basis of repeated measures of ANOVA, there is statistical difference between means of the cross-sectional areas of severe CTS and non-CTS group but the confidence intervals are overlapped. In the moderate CTS the pathologic constellations consist of ischemia, endoneurial edema, inflammation and demyelination of the nerve result in increased cross-sectional areas in both proximal inlet and distal outlet of the carpal tunnel (Rempel et al., 1999; Bayrak et al., 2007). The pathological process may cause nerve changes which are strikingly prominent in US images. Progressive ischemia of the entrapped nerve may cause intraneural fibrosis and axonal degeneration and progressive atrophy of the neural trunk (Rempel et al., 1999; Mondelli et al., 2001; Colak et al., 2007). Highly myelinated large and fast fibers may involve more than small and slow fibers. Sometimes it causes retrograde axonal atrophy in which a decrease in forearm mixed sensory-motor conduction velocity may be a good parameter for diagnosis (Chang et al., 2000, 2004). It was reported that US did not detect more abnormalities than electrophysiologic study in mild CTS (Mondelli et al., 2008).

It seems to be that the quantitative ultrasound findings plays a central role in the diagnosis of the early stages of CTS especially when electrodiagnostic studies are negative or doubtful (Koyuncuoglu et al., 2005). This kind of imaging study is also useful for patients affected with a generalized peripheral neuropathy such as diabetic neuropathy in which diagnosis of CTS is not as easy as normal population. In patients with rheumatoid arthritis and unilateral CTS secondary to mass lesion US could be a useful confirmatory procedure (Beekman and Visser, 2003). To draw a distinction between electrophysiological studies and US, we need to take 
consideration that sonography is pain free, noninvasive, rapid (Visser et al., 2008) and probably cheaper but electrophysiological studies can simultaneously diagnose neuromuscular diseases, radiculopathies and peripheral nerve disorders other than CTS which mimic the symptoms of CTS. It may be the best predictors of symptom severity and functional status in idiopathic CTS rather than US measurements (Kaymak et al., 2008).

The main limitations of our study were the small number of patients and performance of the study in a tertiary care setting. The first problem may cause an artifact when we calculate the performance characteristics of the US diagnostic value; and considering the second problem, our results should be interpreted to tertiary health care centers. The above limitations may cause different cut-off points or contradictory results in patients with severe CTS to some other published studies (El Miedany et al., 2004; Wong et al., 2004).

\section{Conclusion}

This study shows suggestive evidence that there is a progressive reduction in the cross-sectional area of the median nerve when the clinical stage of the patient changes from moderate to severe. Further studies should be done to confirm the hypothesis. Therefore the authors suggest that using high frequency US is a good diagnostic modality in referred patients with moderate CTS to tertiary care centers.

\section{References}

Abicalaf, C. A., de Barros, N., Sernik, R. A., Pimentel, B. F., Braga-Bajak, A., Braga, L., Houvet, P., Brasseur, J. L., Roger, B., Cerri, G. G. (2007) Ultrasound evaluation of patients with carpal tunnel syndrome before and after endoscopic release of the transverse carpal ligament. Clin. Radiol. 62(9), 891-894, discussion 895-896.

American Academy of Neurology (2002) Practice parameter for electrodiagnostic studies in carpal tunnel syndrome: summary statement. Muscle Nerve 25(6), 918-922.

Bayrak, I. K., Bayrak, A. O., Tilki, H. E., Nural, M. S., Sunter, T. (2007) Ultrasonography in carpal tunnel syndrome: Comparison with electrophysiological stage and motor unit number estimate. Muscle Nerve 35(3), 344-348.

Beekman, R., Visser, L. H. (2003) Sonography in the diagnosis of carpal tunnel syndrome: a critical review of the literature. Muscle Nerve 27(1), 26-33.

Buchberger, W., Schon, G., Strasser, K., Jungwirth, W. (1991) High-resolution ultrasonography of the carpal tunnel. J. Ultrasound Med. 10(10), 531-537.

Buchberger, W., Judmaier, W., Birbamer, G., Lener, M., Schmidauer, C. (1992) Carpal tunnel syndrome: diagnosis with high-resolution sonography. AJR Am. J. Roentgenol. 159(4), 793-798.

Chang, M. H., Chiang, H. T., Ger, L. P., Yang, D. A., Lo, Y. K. (2000) The cause of slowed forearm median conduction velocity in carpal tunnel syndrome. Clin. Neurophysiol. 111(6), 1039-1044.

Chang, M. H., Liu, L. H., Wei, S. J., Chiang, H. L., Hsieh, P. F. (2004) Does retrograde axonal atrophy really occur in carpal tunnel syndrome patients with normal forearm conduction velocity? Clin. Neurophysiol. 115(12), 2783-2788. 
Colak, A., Kutlay, M., Pekkafali, Z., Saracoglu, M., Demircan, N., Simsek, H., Akin, O. N., Kibici, K. (2007) Use of sonography in carpal tunnel syndrome surgery. A prospective study. Neurol. Med. Chir. (Tokyo) 47(3), 109-115, discussion 115.

Dawson, D. M. (1993) Entrapment neuropathies of the upper extremities. N. Engl. J. Med. 329(27), 2013-2018.

Duncan, I., Sullivan, P., Lomas, F. (1999) Sonography in the diagnosis of carpal tunnel syndrome. AJR Am. J. Roentgenol. 173(3), 681-684.

El Miedany, Y. M., Aty, S. A., Ashour, S. (2004) Ultrasonography versus nerve conduction study in patients with carpal tunnel syndrome: substantive or complementary tests? Rheumatology 43, 887-895.

Kaymak, B., Ozcakar, L., Cetin, A., Candan Cetin, M., Akinci, A., Hascelik, Z. (2008) A comparison of the benefits of sonography and electrophysiologic measurements as predictors of symptom severity and functional status in patients with carpal tunnel syndrome. Arch. Phys. Med. Rehabil. 89(4), 743-748.

Kele, H., Verheggen, R., Bittermann, H. J., Reimers, C. D. (2003) The potential value of ultrasonography in the evaluation of carpal tunnel syndrome. Neurology 61(3), 389-391.

Keles, I., Kendi, A. T. K., Aydin, G., Orkun, S. (2005) Diagnostic precision of ultrasonography in patients with carpal tunnel syndrome. Am. J. Phys. Med. Rehabil. 84(6), 443-451.

Kotevoglu, N., Gulbahce-Saglam, S. (2005) Ultrasound imaging in the diagnosis of carpal tunnel syndrome and its relevance to clinical evaluation. Joint Bone Spine 72(2), 142-145.

Koyuncuoglu, H. R., Kutluhan, S., Yesildag, A., Oyar, O., Guler, K.,Ozden, A. (2005) The value of ultrasonographic measurement in carpal tunnel syndrome in patients with negative electrodiagnostic tests. Eur. J. Radiol. 56(3), 365-369.

Kwon, B. C., Jung, K. I., Baek, G. H. (2008) Comparison of sonography and electrodiagnostic testing in the diagnosis of carpal tunnel syndrome. J. Hand Surg. Am. 33(1), 65-71.

Leonard, L., Rangan, A., Doyle, G., Taylor, G. (2003) Carpal tunnel syndrome - Is high-frequency ultrasound a useful diagnostic tool? J. Hand Surg. Br. 28(1), 77-79.

Mondelli, M., Reale, F., Padua, R., Aprile, I., Padua, L. (2001) Clinical and neurophysiological outcome of surgery in extreme carpal tunnel syndrome. Clin. Neurophysiol. 112(7), 1237-1242.

Mondelli, M., Filippou, G., Gallo, A., Frediani, B. (2008) Diagnostic utility of ultrasonography versus nerve conduction studies in mild carpal tunnel syndrome. Arthritis Rheum. 59(3), 357-366.

Nakamichi, K., Tachibana, S. (2002) Ultrasonographic measurement of median nerve cross-sectional area in idiopathic carpal tunnel syndrome: Diagnostic accuracy. Muscle Nerve 26(6), 798-803.

Naranjo, A., Ojeda, S., Mendoza, D., Francisco, F., Quevedo, J. C., Erqusquin, C. (2007) What is the diagnostic value of ultrasonography compared to physical evaluation in patients with idiopathic carpal tunnel syndrome? Clin. Exp. Rheumatol. 25(6), 853-859.

Nora, D. B., Becker, J., Ehlers, J. A., Gomes, I. (2004) Clinical features of 1039 patients with neurophysiological diagnosis of carpal tunnel syndrome. Clin. Neurol. Neurosurg. 107(1), 64-69.

Rempel, D., Dahlin, L., Lundborg, G. (1999) Pathophysiology of nerve compression syndromes: response of peripheral nerves to loading. J. Bone Joint Surg. Am. 81(11), 1600-1610.

Sarria, L., Cabada, T., Cozcolluela, R., Martinez-Berganza, T., Garcia, S. (2000) Carpal tunnel syndrome: usefulness of sonography. Eur. Radiol. 10(12), 1920-1925.

Sernik, R. A., Abicalaf, C. A., Pimentel, B. F., Braga-Baiak, A., Braga, L., Cerri, G. G. (2008) Ultrasound features of carpal tunnel syndrome: a prospective case-control study. Skeletal Radiol. 37(1), 49-53.

Stevens, J. C. (1997) AAEM minimonograph \#26: the electrodiagnosis of carpal tunnel syndrome. American Association of Electrodiagnostic Medicine. Muscle Nerve 20(12), 1477-1486.

Visser, L. H., Smidt, M. H., Lee, M. L. (2008) High-resolution sonography versus EMG in the diagnosis of carpal tunnel syndrome. J. Neurol. Neurosurg. Psychiatry 79(1), 63-67.

Ultrasound Evaluation of Carpal Tunnel Syndrome 